RESEARCH REPORT

\title{
Milk consumption, stroke, and heart attack risk: evidence from the Caerphilly cohort of older men
}

\author{
P C Elwood, J J Strain, Paula J Robson, Ann M Fehily, Janie Hughes, Janet Pickering, Andy Ness
}

J Epidemiol Community Health 2005;59:502-505. doi: 10.1136/jech.2004.027904

See end of article for authors' affiliations

....................

Correspondence to: Professor P Elwood, Llandough Hospital Cardiff CF64 2XW', UK. pelwood@doctors.org.uk

Accepted for publication 22 October 2004

\begin{abstract}
Objective: To examine associations between milk consumption and incident heart disease and stroke. Design: A representative population sample of men was asked to weigh and record their food intake for seven days. The total consumption of milk was obtained from these records. Details of all deaths and vascular events were collected during the following 20 years. Incident ischaemic strokes and heart disease events were diagnosed by standard criteria.

Setting: The Caerphilly cohort, a representative population sample of men in South Wales, aged 45-59 when first seen in 1979-83.

Participants: A representative 3:10 subsample of the men in the cohort.

Main results: 665 men ( $87 \%$ of those approached) returned satisfactory seven day diet diaries. After adjustment, the relative odds of an event in the men whose milk consumption was the median or higher, relative to those with lower intakes of milk, were $0.52(0.27$ to 0.99$)$ for an ischaemic stroke and 0.88 (0.56 to 1.40 ) for an ischaemic heart disease event. Deaths from all causes were similar in the two milk consumption groups (relative odds $1.08 ; 0.74$ to 1.58 ).

Conclusions: These results give no convincing evidence of an increased risk of vascular disease from milk drinking. Rather, the subjects who drank more than the median amount of milk had a reduced risk of an ischaemic stroke, and possibly a reduced risk of an ischaemic heart disease event. These conclusions are in agreement with the results of a previously reported overview of 10 large, long term cohort studies based on food frequency intake records.
\end{abstract}

\section{METHODS}

The Caerphilly cohort study was set up in 1979-83. It was based on 2512 men aged 45-59 years. A random sample of 764 men was drawn from the total population sample at baseline. These men were given large capacity spring balance weighing scales with $1 \mathrm{~g}$ divisions. Each man and his partner was given detailed instructions on how to weigh and record every separate food and drink item the man consumed. Food items eaten away from the home were recorded and weights estimated. After a short practice run, a record was then kept for the following seven consecutive days and during this time each man was closely supervised.

Food items were coded according to McCance and Widdowson food tables. ${ }^{11}$ Additional information on the composition of novel foods was sought from food manufacturers. All food codes and general coding was checked by a second nutritionist. Full details of the complete methodology have been given elsewhere. ${ }^{12}$

From these records the total amount of milk consumed was estimated, being the sum of the milk taken in milk containing drinks and with breakfast cereals, together with the amount of milk in recipes such as custards and milk puddings. Any dried milk recorded was converted to an appropriate volume of liquid milk. From the total milk consumed during the seven days a daily average was obtained.

Each man also completed a semi-quantitative food frequency questionnaire with help from his partner, at baseline, and again five years and 10 years after baseline. These asked about the volume of milk consumed (less than 0.5 pints, 0.5 to 1 pint, and greater than one pint per day). The total amounts of milk recorded in the weighed intakes were converted into these same volumes, and the agreement between the questionnaires and the weighed records checked. Agreement was high, and even 10 years after baseline over half the men were weighed intake records kept by a representative subsample of men. 
Table 1 Details of the sample of men within the Caerphilly cohort upon which this report is based, together with the number of vascular events during the 20 year follow up

\begin{tabular}{ll}
\hline Men aged 45-59 years in 1979-83 & \\
\hline Total selected for this study & 764 \\
provided satisfactory diet records & 665 (87\%) \\
Of these, the numbers of men who experienced: & 54 \\
an ischaemic stroke & 139 \\
an ischaemic heart disease event & 181 \\
either of these events & 225 \\
death from any cause & 374 \\
Men who survived free of a vascular disease event & \\
\hline
\end{tabular}

still in the same volume subgroup, and only $4 \%$ had changed their intake by two groups.

Evidence on prevalent vascular disease was collected at baseline by questionnaire together with a 12-lead ECG and all men with evidence of a prior stroke or myocardial infarct have been excluded from the analyses that follow.

The men have all been followed up for 19-23 years since baseline. Subsequently, at five year intervals they were seen in special clinics, questioned about symptoms and illnesses suggestive of a possible stroke or heart attack, and an ECG recorded. Hospital and general practitioner notes were inspected and relevant clinical details extracted. A diagnosis of ischaemic stroke (ICD I63-4 in ICD 10th revision) was made by two expert clinicians, using all the clinical details, including computed tomography, which was available for about half the stroke events. ${ }^{13}$ The term heart attack (ICD I21-5) includes deaths certified as attributable to ischaemic heart disease together with non-fatal myocardial infarction. ${ }^{14}$ Incident vascular events between baseline and 2001 inclusive have been included in the analyses that follow.

Data on factors that might confound the relations of interest were collected, including social class (based upon the most recent occupation of each man and grouped into non-manual and manual), current cigarette consumption (grouped at three levels: never smoked, former smokers, and current smokers), and usual alcohol consumption (grouped into none, below, and above the mean intake of $20.1 \mathrm{~g} /$ day). Height measured on a stadiometer and weight measured on a beam balance were used to derive body mass index $\left(\mathrm{BMI}=\mathrm{kg} / \mathrm{m}^{2}\right)$. Blood pressure was measured at room

Table 2 Milk consumption at baseline in 1979-83 by the 665 men in the cohort

\begin{tabular}{lll}
\hline & \multicolumn{2}{l}{ Number of men } \\
\cline { 2 - 3 } Milk consumption (cc/day)* & Whole milk & Skimmed milk \\
\hline Nil & 18 & 594 \\
$1-49$ & 57 & 20 \\
$50-99$ & 87 & 15 \\
$100-149$ & 98 & 12 \\
$150-199$ & 102 & 9 \\
$200-249$ & 83 & 2 \\
$250-299$ & 65 & 5 \\
$300-349$ & 59 & 3 \\
$350-449$ & 49 & 3 \\
$450+$ & 47 & 2 \\
Median & $187 \mathrm{cc} /$ day & 0 \\
Mean & $211 \mathrm{cc} /$ day & $14 \mathrm{cc} /$ day \\
SD & 152.4 & \\
\hline
\end{tabular}

*Milk consumption includes milk drunk, milk added to tea and other drinks, milk taken with cereals, etc, and milk used in custards and puddings, etc. Milk recorded as "dried" was converted to an equivalent weight of liquid milk. temperature after a prolonged rest, using a random zero sphygmomanometer. Samples of fasting blood were taken for estimation of a wide range of lipid, haemostatic, and other factors of relevance to vascular disease risk. ${ }^{9}$

\section{Statistics}

The men were divided at the median milk intake. Logistic regression analyses were used to estimate the risk of an ischaemic stroke (fatal or non-fatal), an ischaemic heart disease event (myocardial infarction or ischaemic heart disease death), and death from any cause. Risks are expressed as odds for a disease event in the men with the higher milk consumption relative to the risk in the men with lower milk intakes, the latter being set at unity. All probability values are two sided and exact values are stated. Significance is judged as $\mathrm{p}=0.05$ or less.

The confounding factors for which adjustments were made are shown in footnotes to the tables that follow and included age, smoking, social class, BMI, systolic blood pressure, total energy intake, consumption of alcohol, and total fat consumption.

\section{RESULTS}

Of the 764 men selected, 665 men $(87 \%)$ were judged to have kept a satisfactory seven day food intake record. Of these, 54 had an ischaemic stroke and 139 an ischaemic heart disease event during the following 20 years. Some 181 men had had one or other event, 225 men died, and 374 survived free of a vascular disease event (table 1 ).

Table 2 shows the distribution of milk consumption by the men. Only $8 \%$ consumed fat reduced milk at baseline. In 2000 detailed inquiries were made about the use of different types of milk. About $8 \%$ of the milk distributed in the area in 2000 was skimmed, about 50\% semi-skimmed, and about $42 \%$ whole milk. A random sample of 200 of the surviving men were questioned and almost all stated that they had changed from full fat milk to a fat reduced milk within the previous eight years.

Table 3 summarises the associations between milk consumption and factors relevant to vascular disease. Manual workers consumed less milk and more alcohol than workers in non-manual occupations. Men who consumed more milk had lower body mass and higher energy intake, suggesting that they were more active. The fat consumption of the men who drank more milk was slightly higher. Blood pressure was lower, but not significantly, in the men who drank the most milk. Cholesterol levels were similar in the two milk consumption groups.

Milk drinkers seem therefore to differ from non-milk drinkers, but most of the differences are small and it would be impossible to predict how these would together affect relations with vascular disease. The largest difference is in alcohol intake, which was considerably higher in the men who drank the least milk. Alcohol consumption has a negative association with heart disease, so this difference was likely to favour the men who drank the least milk.

Table 4 shows the numbers of vascular events in the two groups of men defined by their milk consumption. The data suggest that the men who had consumed the most milk had a reduced risk for a vascular disease event, and for ischaemic stroke the reduction is statistically significant. These results relate to all the men, but analyses of the men who had consumed full fat milk alone at baseline gave virtually identical results (data not shown).

\section{DISCUSSION}

The Caerphilly cohort is a representative population sample of 2500 older men. The initial response rate (89\%) was high and very few men were lost to follow up. This study is based on a 
Table 3 Characteristics of the subjects within two subgroups defined by milk intake at baseline

\begin{tabular}{|c|c|c|c|}
\hline Mean (or \%) & $\begin{array}{l}\text { Men with median* total } \\
\text { milk intakes or less }\end{array}$ & $\begin{array}{l}\text { Men with total milk intakes } \\
\text { above the median* }\end{array}$ & Probability \\
\hline Number of men & 333 & 332 & \\
\hline Age at baseline (y) & $52.1(4.5)$ & $51.8(4.3)$ & 0.40 \\
\hline Manual workers $†$ & $74 \%$ & $59 \%$ & 0.001 \\
\hline Current smokers & $59 \%$ & $54 \%$ & 0.13 \\
\hline Alcohol intakef (g/day) & 132 (32-273) & $50(0-149)$ & 0.001 \\
\hline BMl‡ (kg/m) & $26.4(3.7)$ & $25.7(3.2)$ & 0.01 \\
\hline Energy intake $(\mathrm{m} J /$ day) & $9.7(2.6)$ & $10.4(2.23)$ & 0.001 \\
\hline Fat intake§ (g/day) & $97(28.4)$ & $101(25.6)$ & 0.001 \\
\hline Systolic BP (mm Hg) & $142.3(20.0)$ & $139.4(18.2)$ & 0.05 \\
\hline \multicolumn{4}{|l|}{ Serum total } \\
\hline Cholesterol $(\mathrm{mM} / \mathrm{I})$ & $6.16(1.22)$ & $6.22(1.16)$ & 0.53 \\
\hline Triglycerides $(\mathrm{mM} / \mathrm{l})$ & $1.96(1.54)$ & $1.66(1.03)$ & 0.001 \\
\hline HDL-cholesterol (mM/I) & $1.39(0.43)$ & $1.83(0.35)$ & 0.07 \\
\hline
\end{tabular}

The data shown are percentages, or means and SDs as appropriate. Missing values as follows: smoking, four men occupation (social class) 14 men; serum total cholesterol 38 men; triglycerides 47 men; homocysteine 156 men. These were equally divided between the two subgroups of the men and for no other variable were there missing values. *The median intake of all milk and from all sources was $195 \mathrm{cc}$ per day. †Based on the man's occupation at baseline, using the registrar general UK's classification. ¥Median intake and interquartile range. §Estimates adjusted for energy intake. 'Estimates derived from fasting blood samples.

representative subsample of these men. Again, the response rate was high $(87 \%)$ and follow up was virtually complete.

The 665 men in this subsample kept a weighed food intake record for seven days and these show that the men with the greater consumption of milk experienced a reduction in the risk of ischaemic stroke and a possible reduction in ischaemic heart disease risk.

These results are closely similar both to the results we found for 2403 men in the full Caerphilly cohort who had completed food frequency questionnaires at baseline, ${ }^{5}$ and are also similar to the results of an overview ${ }^{10}$ of the 10 major cohort studies in which milk consumption had been recorded..$^{515-23}$ In this overview of 200000 subjects, with 8500 vascular events, the pooled estimate of relative odds of the subjects with the highest consumption of milk, was 0.87 (95\%CI 0.74 to 1.03) for ischaemic heart disease, 0.83 (0.77 to 0.90$)$ for ischaemic stroke, and 0.84 ( 0.78 to 0.90$)$ for either event.
Explanations of these results other than a beneficial effect of milk would seem to be unlikely. Residual confounding is always a possibility in a cohort study, but adjustments have been made in this study, and in each of the published studies for a wide range of factors. It would certainly seem unlikely that confounding, or bias, could have turned a harmful association with milk drinking into the observed protective effect. Furthermore, had there been residual confounding of the relations with the disease events in this cohort, because vascular deaths constitute more than half the total deaths in a community you would reasonably expect a difference in total deaths, similar in direction to those for vascular disease. This is not shown, the relative odds for all cause deaths in the two groups being almost identical (table 4).

It seems to be widely believed however that milk consumption increases the risk of vascular disease, and should therefore be limited. This belief seems to be founded

Table 4 Relative odds of a disease event in the two groups of men defined by milk consumption

\begin{tabular}{|c|c|c|c|}
\hline \multirow[b]{2}{*}{ Milk consumption } & \multirow[b]{2}{*}{ Incident disease events } & \multicolumn{2}{|c|}{ Relative odds for an event } \\
\hline & & Adjusted* & Adjusted $\dagger$ \\
\hline \multicolumn{4}{|l|}{ Milk intake: } \\
\hline below the median & 35 strokes & 1.00 & 1.00 \\
\hline at or above median & 18 strokes & 0.52 & 0.52 \\
\hline & & (0.27 to 0.93 ) & (0.27 to 0.99$)$ \\
\hline & & $p=0.03$ & $p=0.05$ \\
\hline \multicolumn{4}{|l|}{ Milk intake: } \\
\hline below the median & $64 \mathrm{HD}$ events & 1.00 & 1.00 \\
\hline at or above median & $50 \mathrm{IHD}$ events & 0.75 & 0.88 \\
\hline & & $(0.49$ to 1.16$)$ & (0.56 to 1.40$)$ \\
\hline & & $p=0.20$ & $p=0.59$ \\
\hline \multicolumn{4}{|l|}{ Milk intake: } \\
\hline below the median & 88 total events $\ddagger$ & 1.00 & 1.00 \\
\hline at or above median & 64 total events $\ddagger$ & 0.67 & 0.76 \\
\hline & & (0.44 to 0.98$)$ & (0.50 to 1.15$)$ \\
\hline & & $p=0.04$ & $p=0.19$ \\
\hline \multicolumn{4}{|l|}{ Milk intake: } \\
\hline below the median & 116 total deaths $\S$ & 1.00 & 1.00 \\
\hline at or above median & 109 total deaths§ & 1.11 & 1.08 \\
\hline & & $(0.78$ to 1.60$)$ & (0.74 to 1.58 ) \\
\hline & & $p=0.56$ & $p=0.67$ \\
\hline
\end{tabular}

*Relative odds unadjusted. †Relative odds adjusted for age, total energy, smoking, social class. $¥$ Relative odds adjusted for above and BMI, systolic blood pressure, consumption of alcohol, and fat consumption. §Total events are ischaemic strokes and ischaemic heart disease combined. TTotal deaths are deaths from any cause. Men who had had a prior stroke have been omitted from the data on stoke, and men with a prior IHD event have been omitted from the data on IHD. 


\section{What the paper adds}

- The paper challenges the belief that because milk drinking raises blood cholesterol level it increases the risk of vascular disease.

- By accurately characterising the usual diets of a representative sample of male subjects it adds to the already substantial body of evidence from cohort studies that milk drinking is associated with a reduced incidence of stroke and ischaemic heart disease.

upon the fact that many cross sectional studies have shown that milk intake is positively related to blood cholesterol levels and an increase in milk consumption is followed by an increase in cholesterol level. ${ }^{1}{ }^{15} 1624$ An important difficulty in assessing the importance of this relation is the fact that milk consumption is at the same time negatively related to blood pressure, $^{25} 26$ an equally important risk factor for heart disease, and a much greater factor in ischaemic stroke risk. For example, in the Puerto Rico cohort study the men who drank the most milk had half the prevalence of hypertension compared with those who drank no milk. ${ }^{27}$

A second source of evidence suggesting harm from milk is ecological, and a number of studies have shown positive correlations between milk production in selected countries and heart disease mortality. ${ }^{3}{ }^{28}$ An important difficulty in interpreting conclusions based on such data is an absence, and usually a complete absence, of adjustments for the effects of confounding factors.

Randomised, controlled, intervention trials would undoubtedly give the best evidence on the relations between a factor, dietary or other, and the risk of a disease. Such a study would however be virtually impossible in the case of milk. To have reasonable power to detect either a $10 \%$ increase, or a $10 \%$ reduction in heart disease events, a clinical trial would have to include more than 20000 subjects, and these would have to agree to either (at random) avoid all milk for perhaps five years, or consume reasonably large amounts of milk for the same period. No such study is likely to be acceptable.

\section{Policy implications}

The present perception of milk as harmful, in increasing cardiovascular risk, should be challenged and every effort should be made to restored to its rightful place in a healthy diet.

\section{CONCLUSIONS}

In the absence of evidence from intervention trials, the best available evidence on milk consumption and vascular disease risk comes from prospective, cohort studies. One such study is described in which milk consumption, estimated from seven day weighed intake records, shows a negative association with ischaemic stroke in the men with the greatest milk consumption, and, possibly, with heart disease.

\section{ACKNOWLEDGEMENTS}

The Caerphilly study was conducted by the former MRC Epidemiology Unit (South Wales) and was funded by the Medical Research Council of the United Kingdom. The archive is now maintained by the Department of Social Medicine in the University of Bristol, UK.

\section{Authors' affiliations}

P C Elwood, Visiting Professor, University of Ulster, Coleraine, Northern Ireland

J J Strain, P J Robson, Northern Ireland Centre for Food and Health

(NICHE), University of Ulster

A M Fehily, Consultant Nutritionist

J Hughes, J Pickering, University of Wales College of Medicine, Cardiff, UK

A Ness, University of Bristol, Bristol, UK

Funding: The Medical Research Council UK and the University of Ulster UK. Janet Pickering and Janie Hughes are supported by the UK Food Standards Agency.

Conflicts of interest: none declared.

\section{REFERENCES}

1 Roberts DCK, Truswell AS, Sullivan DR, et al. Milk, plasma cholesterol and controls in nutritional experiments. Atherosclerosis 1982;42:323-5.

2 Steinmetz KA, Childs MT, Stimson C, et al. Effect of consumption of whole milk and skim milk on blood lipids profiles in healthy men. Am J Clin Nutr 1994:59:612-18.

3 Segall JJ. Is milk a coronary health hazard? Br J Prev Soc Med 1977;31:81-5.

4 Moss M, Freed D. The cow and the coronary: epidemiology, biochemistry and immunology. Int J Cardiol 2003;87:203-16.

5 Elwood PC, Pickering J, Fehily AM, et al. Milk drinking, ischaemic heart disease and ischaemic stroke. Il. evidence from cohort studies. Eur J Clin Nutr 2004;58:718-24

6 Day N, McKeown N, Wong M, et al. Epidemiologic assessment of diet: a comparison of a 7-day dairy with a food frequency questionnaire using urinary markers of nitrogen, potassium and sodium. Int J Epidemiol 2001;30:309-17.

7 Bingham SA, Welch A, McTaggart, et al. Nutritional methods in the European prospective investigation of cancer in Norfolk. Public Health Nutrition 2001;4:847-58.

8 Bingham SA, Luben R, Welch A, et al. Are imprecise methods obscuring a relation between fat and breast cancer? Lancet 2003;362:212-14.

9 The Caerphilly and Speedwell Collaborative Group. Caerphilly and Speedwell collaborative heart disease studies. J Epidemiol Community Health 1984;38:259-62

10 Elwood PC, Pickering JE, Fehily AM, et al. Milk drinking, ischaemic heart disease and ischaemic stroke. I. Evidence from the Caerphilly cohort. Eur J Clin Nutr 2004;58:711-17.

11 Paul AA, Southgate DAT. McCance and Widdowson's the composition of foods. 4th ed. London: HMSO, 1978.

12 Fehily AM, Phillips KM, Sweetnam PM. A weighed dietary survey of men in Caerphilly, South Wales. Hum Nutr Appl Nutr 1984;38:270-6.

13 Greenwood R, McCarron P, Elwood PC, et al. The incidence and aetiology of stroke in the Caerphilly and Speedwell Collaborative studies. I Methods and incidence of events. Public Health 2001;115:4-11.

14 Bainton D, Baker IA, Sweetnam PM, et al. Prevalence of ischaemic heart disease: the Caerphilly and Speedwell surveys. Br Heart J 1988;59:201-6.

15 Abbott RD, Curb JD, Rodriguez BL, et al. Effect of dietary calcium and milk consumption on risk of thrombo-embolic stroke in older middle aged men: the Honolulu heart program. Stroke 1996;27:813-18.

16 Ness AR, Davey Smith G, Hart C. Milk, coronary heart disease and mortality. J Epidemiol Community Health 2001;55:379-82.

17 Bostic RM, Kushi LH, Wu Y, et al: Relation of calcium, vitamin D, and dairy food intake to ischaemic heart disease mortality among postmenopausal women. Am J Epidemiol 1999;149:151-61.

18 Shaper AG, Wannamethee G, Walker M. Milk, butter and heart disease. BMJ $1991 ; 302: 786-7$

19 Mann JI, Appleby PN, Key TJ, et al. Dietary determinants of ischaemic heart disease in health conscious individuals. Heart 1997;78:450-5.

20 Iso H, Stampfer MJ, Manson JE, et al. Prospective study of calcium, potassium and magnesium intake and risk of stroke in women. Stroke 1999:30:1772-9.

21 Kinjo Y, Beral V, Akiba S, et al. Possible protective effect of milk and fish for cerebrovascular disease mortality in Japan. J Epidemiol 1999;9:268-74.

22 Snowdon DA, Phillips RL, Frazer GE. Meat consumption and fatal ischaemic heart disease. Prev Med 1984;13:490-500.

23 Vijver L Van der, Waal M Van der, Wetterings KGC, et al. Calcium intake and 28-year cardiovascular and coronary heart disease mortality in Dutch civil servants. Int J Epidemiol 1992;21:36-9.

24 Nagaya T, Yoshida H, Hayashi T, et al. Serum lipid profile in relation to milk consumption in a Japanese population. J Am Coll Nutr 1996;15:625-9.

25 Ackley S, Barrett-Connor E, Suarez L. Dairy products, calcium and blood pressure. Am J Nutr 1983;38:457-61.

26 Pryer J, Cappuccio FP, Elliott P. Dietary calcium and blood pressure: a review of the observational studies. J Hum Hypertens 1995;9:597-604.

27 Garcia-Palmieri MR, Costas R, Cruz-Vidal M, et al. Milk consumption, calcium intake and decreased hypertension in Puerto Rico. Puerto Rico heart health programme study. Hypertension 1984;6:322-8.

28 Seeley S. Milk and atheroma. In: Freed DJL, ed. Health hazards of milk. Eastbourne: Balliere Tindall, 1984:213-29. 